\title{
A CASE FOR USING SWIVL FOR DIGITAL OBSERVATION IN AN ONLINE OR BLENDED LEARNING ENVIRONMENT
}

\section{Selina McCoy 1 \\ Aoife Lynam 2 * \\ Mary Kelly 2}

1 The Economic and Social Research Institute, Dublin, Ireland

2 Hibernia College, Dublin, Ireland

*Address all correspondence to: Aoife Lynam, Hibernia College, Block B, The Merrion Centre, Merrion Rd, Dublin, Ireland; Tel.: +353 1799 9239;

E-mail: alynam@hiberniacollege.net

\begin{abstract}
This paper examines the use of digital video in order to enhance professional development for online and blended learning programs in higher education, with particular reference to initial teacher education (ITE). While digital observation in the context of teacher education has been the subject of some discussion, the technology considered in this article is relatively new. Swivl is an innovative technology which allows for nonintrusive digital observation of, for example, school placement. The benefits of using digital observation for professional development are numerous, including the recording of information that may not otherwise be captured and allowing for the retaining of that information for reflection and analysis purposes. This paper assesses the potential benefits for both staff and students who work in an online and blended learning environment, as well as identifying some challenges this technology may present. The paper places a particular focus on the practical application of Swivl technology in a blended learning postgraduate program for ITE in Ireland. The aim of this paper is twofold: (1) to explore the use of an innovative technology called Swivl for online or blended higher education and (2) to present an overview of a proposed pilot study in which a randomized controlled trial group of student teachers $(N=50)$ will use Swivl to self-reflect during school placement. A second paper, in early 2019 , will provide a detailed analysis of the impact of the use of digital technology in a treatment group as part of the pilot study.
\end{abstract}

KEY WORDS: digital observation, technology-enabled education, Swivl, blended learning, online learning, assessment, professional development, technology 


\section{INTRODUCTION}

Technological advances have the potential to play a central role in enhancing teacher education in a number of respects. First, digital technologies and online learning can improve access to teacher education, allowing those who were constrained due to financial or logistic barriers to participate (Anderson and Elloumi, 2004; Ololube et al., 2017).

Second, technological developments have the potential to enhance the effectiveness of teaching practice. Alongside coursework, the Organization for Economic Cooperation and Development (2009) highlighted that classroom observations are a key source of evidence for teacher evaluation and professional development. Many student teachers long for more hands-on experiences in the classroom, particularly for the opportunities to enhance skills and develop reflective thinking (Cochran-Smith and Power, 2010; Zeichner, 2012). Digital technologies provide significant opportunities, given that in-person observation may be limited in what is captured and may not accurately reflect that teacher's capacity, in some cases due to increased stress (Aubusson et al., 2007). In any case, in-person observations do not allow student teachers to see themselves, thus limiting their opportunity for self-reflection. Digital observation through Swivl can allow more meaningful and reflective teaching practice experiences. Research indicates that teachers can better understand and examine the complexities of their classroom and critically evaluate their own practice using digital observation (Hartford and MacRuairc, 2008; Chilton and McCracken, 2017; Osmanoglu, 2016). Video technology used synchronously and asynchronously can extend the quality of classroom observation, analysis, and reflection for teachers (Donlon, 2017; Dyke et al., 2008; Lebak, 2017; Mabunda, 2013).

Third, digital technologies can enhance the efficiency of teacher education - in particular, through reducing some of the financial and logistical constraints of traditional classroombased teacher education and in-person teaching practice observation. Finally, through the seamless integration of digital technologies in teacher education and teacher practice, teachers are learning firsthand of the benefits of online and blended learning approaches. In Ireland, as elsewhere, policy makers are increasingly embracing the potential for digital technologies and online learning to enhance teaching and learning, right across the education system (DES, 2013; DES, 2017; European Commission, 2015). Equipping student teachers with the skills and confidence to seamlessly embed technology into their teaching is fundamental if broader policy goals are to be achieved (McCoy et al., 2016).

\section{IRELAND: A CASE STUDY}

This study examines the use of digital video in teacher education in one college, Hibernia College, in Ireland. In considering the potential for innovations in teacher education, 
Ireland is an interesting case study for a number of reasons. Recent times have seen growing concerns over a shortage of qualified primary and secondary school teachers (Irish Times, 2018). In March 2018, the Minister for Education established a Teacher Supply Steering Group to examine shortages in key subject areas in science, technology, engineering, and mathematics (STEM), digital learning, and foreign languages. Digital technologies such as Swivl, integrated into online and blended learning programs, can allow greater access to teacher education, particularly for those constrained by financial barriers or geographical location. Hence, Swivl technology can support both a timely response to critical teacher shortages and policy objectives on widening access to teacher education and promoting the diversification of the teaching profession (Darmody and Smyth, 2016).

Hibernia College is the first accredited blended learning college in Ireland and provides the largest number of primary teachers in the country. For nearly 20 years, the private college has been exploring new and innovative ways to enhance the way teachers learn the professional requirements of teaching. The use of Swivl technology is the latest innovation, allowing student teachers to fully engage with their teaching practice and learn through self-reflection.

Ireland is also interesting, as recent years have seen significant policy focus and investment in enhancing digital technologies and digital education across primary and secondary schools. The Action Plan for Education (2018) and Digital Learning Planning Guidelines (2017) envisage digital technologies as being embedded across the entire curriculum and central in enhancing the quality of teaching and learning. Research shows that school leaders and teachers alike have highlighted the benefits of digital technologies in the classroom, enhancing and expanding teaching and learning methodologies (McCoy, 2016). However, research also shows that teacher skills and confidence in using digital technologies serve as a barrier (McCoy et al., 2016). The integration of Swivl and other technologies into teacher education have significant potential to enhance the capacity and confidence of teachers to innovate and evolve as new technologies emerge. These developments can thus support broader policy objectives around transforming teaching, learning, and assessment for all learners.

\section{THE PILOT: TRIALLING TECHNOLOGY FOR THE ENHANCEMENT OF SELF-REFLECTION}

Nagro and deBetterncourt (2018) define reflective ability as the quantifiable ability to critically review, analyze, and evaluate a teaching situation in order to learn from the experience and apply that insight to future situations. The pilot, taking place in late 2018, will explore remote digital recording and its effect on student teacher self-reflection. The 
digital technology being used is Swivl (see www.swivl.com), an innovative technology that allows for nonintrusive digital observation of practice. Video reflection has been found to optimize the learning experience as well as result in higher levels of immersion in and motivation for genuine teaching reflection (Nagro and deBetterncourt, 2018). Swivl functions through a moveable base in which an iPad or tablet is placed. The student teacher wears a small device on a lanyard that captures audio and contains a tracker which allows the Swivl to automatically adjust position as the teacher moves around the classroom. To use the Swivl, the student teacher must start the video camera on the iPad or tablet and the Swivl will do the rest. With Swivl, there is also the opportunity to use additional cameras and markers to allow more to be seen and heard (e.g., pupil conversations). Swivl has the potential to allow for synchronous and asynchronous observation and for school placement supervisors to give specific feedback for professional development and to engage in conversations about their practice. It allows student teachers to reflect upon their own practice by watching videos and allows them to collaborate, connect, and converse with their placement supervisor (Chilton and McCracken, 2017).

The proposed study was developed from research (Kane et al., 2016) at Harvard University called The Best Foot Forward (BFF). The BFF used a video-based teacher $(n=$ 347 ) evaluation system among a group of individuals who were randomly assigned to treatment and control groups. The treatment group submitted their own recorded class videos instead of the more traditional in-person observations. The treatment group was given control over which lessons (three out of an average of 13 recordings) would be submitted for observation, therefore using the video to put their "best foot forward." Overall the findings showed that video-based observations generated larger improvements in student achievement than in-person observations (Kane et al., 2016). This research highlighted the benefits for teachers, school administrators, and ITEs (Kane et al., 2016). For teachers, the findings showed that the use and selection of videos allowed for greater self-reflection among the treatment group. In fact, the study shows this group to be more self-critical, rating their instruction lower than the control group. This may be due to the fact that teachers in this group had to choose from a set of recorded lessons which may have led them to record more lessons (Kane et al. 2016). Teachers in the treatment group also reported feeling more supported by their supervisors and found video observations to be fairer than the traditional in-class observation method.

Other international studies concur that video technology demonstrates clear benefits for preservice teacher development and show how, using video-based examples, teachers can more easily examine the complexities of their classroom and critically evaluate their practice (Harford and MacRuairc, 2008; Chilton and McCracken, 2017; Osmanoglu, 2016). 
The Teaching Council (2017) states that during school placement ITEs should allow for the development of a more reflective, enquiry-oriented approach to school placement. Thus, this pilot will explore how digital observation impacts student teachers' $(n=50)$ selfreflection in a randomized control trial. In their paper, Chilton and McCracken (2017) highlighted the opportunities for reflective practice using Swivl technology. Thus, it is both timely and necessary to examine how digital observation enhances self-reflection in professional practice. During school placement, Swivl will allow student teachers to record lessons during school placement and self-reflect while playing back the footage in order to ascertain how effective or ineffective their lesson was. This pilot will seek to understand:

1. To what extent does the use of digital recordings to reflect on practice (a) result in changes in student teachers' self-efficacy around teaching and (b) enhance student teachers' self-reflective skills?

2. How does the assessment by the school placement supervisor compare with an assessment of the digital recordings compiled by the student teacher? Are the two approaches capturing the same criteria?

\section{PARTICIPANTS}

A total of 110 students self-selected to take part in the research during their second school placement. A randomized control trial sample of student teachers $(n=50)$ were assigned to matched treatment $(n=25)$ and the control groups $(n=25)$. The following criteria were utilized for the selection: (1) sex, (2) teaching practice grades, and (3) the type of school (e.g., designated disadvantaged, nondisadvantaged). Student teachers choose their own schools for school placement and thus the schools are generally in their own locality with principals often prioritizing past pupils.

\section{PILOT METHODOLOGY}

A mixed method approach is being used to fully understand the experiences of learners undertaking this new approach. The first research question will be answered via data collected through (a) a survey before school placement, (b) a survey after school placement, and (c) an interview after school placement (via Blackboard Collaborate, an online collaboration platform). The second research question will be answered through a review of the treatment group $(n=25)$ recordings and subsequent written reports by school placement tutors. The student teachers will not have access to any additional feedback or written reports so that there is no impact on the formal assessment that is taking place. The Hibernia College school placement tutors will compare evaluations of student teacher placements using the video technology and evaluations through the traditional in-person classroom observations. 
During the data collection phase the Swivl camera will be given to the treatment group $(n=$ 25) and placed at the back of the classroom. The student teacher will wear a lanyard containing a tracking mechanism which allows the camera to follow them as they move around the classroom. The lanyard contains a microphone so that the teacher and pupil responses can be heard clearly. While the focus of the camera will be on the teacher, pupil's faces and responses in the classroom may be seen and heard on the camera, which is why informed parental consent is compulsory for all pupils participating. In a situation where some parents do not give consent, it is up to the school principal and/or Board of Management (i.e., a board of management manages the school on behalf of the patron) to decide how best to proceed. They can, for example: (1) only use the Swivl camera when the pupil(s) who do not have parental consent are not in the classroom or (2) decide not to use the Swivl camera and thus remove themselves from the research project.

Student teachers will be provided with information and a PowerPoint presentation on how to inform the pupils in their class about the research in an age-appropriate manner. A webinar will be provided for students to give them information on how to set up the Swivl and to answer any questions that they may have. During the five weeks where the treatment group will be teaching in the classroom, they will use the Swivl software to record three lessons: one at the beginning (week 2), one in the middle (week 4), and one at the end (week 6). An e-mail prompt will be sent to the treatment group at the beginning of weeks 2, 4, and 6 in order to remind them about recording one lesson that week.

\section{ETHICAL CHALLENGES}

Many of the concerns around the use of digital video in classrooms relate to ethical standards and the protection of all participants. For this study, ethical approval was granted by Hibernia College Ethics Committee and the researchers will follow the British Education Research Association (2018) ethical guidelines for research in education. Student teachers will sign a confidentiality agreement whereby they confirm that they will not share any videos with other student teachers. All of the video recordings will be saved onto the tablet and uploaded to an Amazon Cloud storage server based in the EU via a secure connection called the Swivl Cloud service. Recorded video data will be stored on an SD card in the tablet. To ensure privacy, the tablet and the SD card will be encrypted and secured with a pin. The transfer of video between the tablet and the cloud storage server will be over a secure SSL connection. Student teachers will be made aware that any recording made using the kit will belong to Hibernia College and will be permanently deleted after 30 days. Student teachers will be informed that any copying or sharing of any recorded video material from the tablet to any other device, service, or e-mail account is strictly prohibited and would result in penalties under the data protection act (General Data 
Protection Regulation, 1988-2018). Student teachers will be signing a confidentiality agreement whereby they acknowledge that they cannot share any video content nor can it be used for any other purpose. When the project is complete, all video recordings will be permanently deleted from the tablet and from the cloud storage after 30 days.

\section{POTENTIAL FOR INNOVATION IN ONLINE AND BLENDED LEARNING}

Swivl could potentially have many benefits for innovation in online and blended learning. Kansas State University (KSU) is a prime example of innovation through the successful integration of Swivl in an online environment. Prior to using Swivl, KSU placed over 400 student teachers in schools for three early field experiences, and this culminated in nearly 2000 placement visits each year (Allen et al., 2014). Following five years of field-based research, they currently use a sole supervision model on a Master of Arts in Teaching program and a hybrid format for supervision on their undergraduate campus-based program (Allen et al., 2018). While there have been many successes in the development of their supervision and mentoring during the remote supervision, there have also been, as expected, some challenges. For example, the lack of a physically present supervisor in the classroom (a) can lead to mistrust, (b) not all teachers and supervisors are supportive of distant supervision, (c) classroom teachers desire face-to-face communication with a university representative, and (d) there are legal issues in relation to privacy to consider (Allen et al., 2018). Notwithstanding these barriers, they have found that capturing teaching via video and storing it in an unlimited cloud-based storage facility has allowed for sustained, ongoing dialogue in an environment that facilitates the growth process of preservice teachers (Allen et al., 2018).

\section{CONCLUSION}

In this paper, we discussed the current understanding of digital observation for professional development in blended and online learning environments and how Swivl technology may provide important opportunities in teacher education. This paper presented a study using Swivl digital video in teacher education in one college in Ireland, Hibernia College. A randomized control study is currently underway, in which student teachers are assigned to matched treatments (using Swivl technology) and control (inperson observation) groups. Mixed method data is being collected through surveys with student teachers before and after school placement and an interview after placement. Written reports from school placement tutors will also form part of the evidence. A second paper in early 2019 will provide a detailed analysis of the results of the study.

Digital technologies such as Swivl can support policy objectives on widening access to teacher education and enhance efficiencies in the provision of teacher education. There has also been much policy focus on digital technologies in the classroom, aiming to embed 
digital technologies across the entire curriculum and enhance the quality of teaching and learning. However, the successful integration of digital technologies in classrooms depends greatly on the skills and competencies of teachers (Howard, 2013; Fraillon et al., 2014; McCoy et al., 2016). Further, Haydn (2014) argues that it is important to acknowledge that digital skills are not sufficient; teachers need to be sufficiently prepared to use these skills in a "pedagogically effective way" which enhances student learning outcomes. The integration of Swivl and other digital technologies into teacher education can play an important role in achieving these goals.

Finally, while Swivl has been discussed in this paper in relation to teacher education, it is evident that this technology can be used across any profession which is looking for authentic ways to assess and develop real-life practicum experiences. Swivl has the potential to reform the reflective and evaluative processes currently in place for online and blended education environments. However, introducing digital observation to the classroom will not be without its challenges, many of which relate to the importance of high ethical standards, data protection regulations, and the protection of all participants. Ensuring these risks are fully addressed will be central if the potential of Swivl technology for supporting the development of a more reflective, enquiry-based approach to school placement is to be realized (Teaching Council, 2017).

\section{REFERENCES}

Allen, D.S., Perl, M., Goodson, L., and Sprouse, T.K., Changing Traditions: Supervision, Co-Teaching, and Lessons Learned in a Professional Development School Partnership, Educ. Considerations, vol. 42, no. 1, pp. 19-29, 2014.

Allen, D.S., Wood, A.J., Sponberg, E., and Arnold, T.M., Digitally Mediated Supervision: Redefining Feedback Systems in Field-Based Courses, in Handbook of Research on Field-Based Teacher Education, T.E. Hodges and C. Angela, Eds., Hersey, PA: IGI Global, pp. 542-564, 2018.

Anderson, T. and Elloumi, F. Theory and Practice of Online Learning, Canada: Athabasca University, 2004.

Chilton, H. and McCracken, W., New Technology, Changing Pedagogies? Exploring the Concept of Remote Teaching Placement Supervision, Higher Educ. Pedagogies, vol. 2, no. 1, pp. 116-30, 2017.

Cochran-Smith, M. and Power, C., New Directions for Teacher Preparation, Educ. Leadership, vol. 19, pp. 6-13, 2010.

Darmody, M. and Smyth, E., Entry to Programmes of Initial Teacher Education, Dublin: The Teaching Council and The Economic and Social Research Institute, 2016. 
Department of Education and Skills, Digital Strategy for Schools 2015-2020, Dublin: Department of Education and Skills, 2013.

Department of Education and Skills, Digital Learning Planning Guidelines, Dublin: Department of Education and Skills, 2017.

Department of Education and Skills, Action Plan for Education 2018, Dublin: Department of Education and Skills, retrieved Sept. 18, 2018, from https://www.education.ie/en/TheDepartment/Action-Plan-for-Education-2016-2019/.

Donlon, E., The Use of a Custom-Built Online Environment for Communication with and Support of Student-Teachers during School Placement, Teaching Educ., pp. 1-15, 2017.

Dyke, M., Harding, A., and Liddon, S., How Can Online Observation Support the Assessment and Feedback, on Classroom Performance, to Trainee Teachers at a Distance and in Real Time? J. Further Higher Educ., vol. 32, no. 1, pp. 37-46, 2008.

European Commission, Digital Agenda in the Europe 2020 Strategy, Brussels: European Commission, 2015.

Fraillon, J., Ainley, J., Schulz, W., Friedman, T., and Gebhardt, E., Preparing for Life in a Digital Age, The IEA International Computer and Information Literacy Study International Report, Melbourne: IEA/Springer Open Access, 2014.

General Data Protection Regulation, Regulation (EU) 2016/679 of the European Parliament and of the Council of 27 April 2016 on the Protection of Natural Persons with Regard to the Processing of Personal Data and on the Free Movement of Such Data, and Repealing Directive 95/46/EC (General Data Protection Regulation), retrieved Sept. 18, 2018, from https://eur-lex.europa.eu/legal-content/EN/TXT/PDF/?uri=CELEX:32016R0679. Harford, J. and MacRuairc, G., Engaging Student Teachers in Meaningful Reflective Practice, Teaching Teacher Educ., vol. 24, no. 7, pp. 1884-1892, 2008.

Haydn, T., How do you Get Pre-Service Teachers to Become 'Good at ICT' in Their Subject Teaching? The Views of Expert Practitioners, Technol. Pedagogy Educ., vol. 23, no. 4, pp. 455-469, 2014.

Howard, S.K., Risk-Aversion: Understanding Teachers' Resistance to Technology Integration, Technol. Pedagogy Educ., vol. 22, no. 3, pp. 357-372, 2013.

Irish Times, Teacher Shortages at Second-Level Set to Deepen, retrieved Sept. 18, 2018, from https://www.irishtimes.com/news/education/teacher-shortages-at-second-level-set-todeepen-1.3560594.

Lebak, K., Using Video-Support Reflection in Peer Groups to Increase Instructional Effectiveness, Reflective Practice, vol. 18, no. 1, pp. 94-111, 2017. 
Mabunda, P.L., Towards a Theoretical Framework for the Use of ICT Strategies for Teaching Practicum Supervision, Afr. Educ. Rev., vol. 10, no. 1, pp. S7-S27, 2013.

McCoy, S., Lyons, S., Coyne, B., and Darmody, M., Teaching and Learning in SecondLevel Schools at the Advent of High-Speed Broadband, Dublin: The Economic and Social Research Institute, 2016.

Nagro, S.A. and deBettencourt, L.U., Reflection Activities within Clinical Experiences: An Important Component of Field-Based Teacher Education, in Handbook of Research on Field-Based Teacher Education, T.E. Hodges and C. Angela, Eds., Hershey, PA: IGI Global, pp. 565-586, 2018

Ololube, N.P., Kpolovie, P.J., and Rhodes, T., From "My Work" to "Our Work": A Return to the Mission of Higher Education, Int. J. Innovations Online Educ., vol. 1, no. 1, pp. 1-8, 2017.

Osmanoglu, A., Prospective Teachers' Teaching Experience: Teacher Learning through the Use of Video, Educ. Res., vol. 58, no. 1, pp. 39-55, 2016.

The Teaching Council, Initial Teacher Education: Criteria and Guidelines for Program Providers, 2017, retrieved Sept. 18, 2018, from https://www.teachingcouncil.ie/en/ Publications/Teacher-Education/Initial-Teacher-Education-Criteria-and-Guidelines-forProgramme-Providers.pdf.

Zeichner, K., The Turn Once Again Towards Practice-Based Teacher Education, J. Teacher Educ., vol. 63, no. 5, pp. 376-382, 2012. 